\title{
Sensitivity of chemistry-transport model simulations to the duration of chemical and transport operators: a case study with GEOS-Chem v10-01
}

\author{
Sajeev Philip ${ }^{1}$, Randall V. Martin ${ }^{1,2}$, and Christoph A. Keller ${ }^{3, a}$ \\ ${ }^{1}$ Department of Physics and Atmospheric Science, Dalhousie University, Halifax, Nova Scotia, Canada \\ ${ }^{2}$ Harvard-Smithsonian Center for Astrophysics, Cambridge, Massachusetts, USA \\ ${ }^{3}$ School of Engineering and Applied Sciences, Harvard University, Cambridge, Massachusetts, USA \\ ${ }^{a}$ now at: Universities Space Research Association/GESTAR, NASA GMAO Code 610.1, Greenbelt, Maryland, USA
}

Correspondence to: Sajeev Philip (sj207331@ dal.ca)

Received: 15 September 2015 - Published in Geosci. Model Dev. Discuss.: 3 November 2015

Revised: 21 April 2016 - Accepted: 22 April 2016 - Published: 3 May 2016

\begin{abstract}
Chemistry-transport models involve considerable computational expense. Fine temporal resolution offers accuracy at the expense of computation time. Assessment is needed of the sensitivity of simulation accuracy to the duration of chemical and transport operators. We conduct a series of simulations with the GEOS-Chem chemistry-transport model at different temporal and spatial resolutions to examine the sensitivity of simulated atmospheric composition to operator duration. Subsequently, we compare the species simulated with operator durations from 10 to $60 \mathrm{~min}$ as typically used by global chemistry-transport models, and identify the operator durations that optimize both computational expense and simulation accuracy. We find that longer continuous transport operator duration increases concentrations of emitted species such as nitrogen oxides and carbon monoxide since a more homogeneous distribution reduces loss through chemical reactions and dry deposition. The increased concentrations of ozone precursors increase ozone production with longer transport operator duration. Longer chemical operator duration decreases sulfate and ammonium but increases nitrate due to feedbacks with in-cloud sulfur dioxide oxidation and aerosol thermodynamics. The simulation duration decreases by up to a factor of 5 from fine $(5 \mathrm{~min})$ to coarse $(60 \mathrm{~min})$ operator duration. We assess the change in simulation accuracy with resolution by comparing the root mean square difference in ground-level concentrations of nitrogen oxides, secondary inorganic aerosols, ozone and carbon monoxide with a finer temporal or spatial resolution taken as "truth". Relative simulation error for these species
\end{abstract}

increases by more than a factor of 5 from the shortest ( $5 \mathrm{~min}$ ) to longest $(60 \mathrm{~min})$ operator duration. Chemical operator duration twice that of the transport operator duration offers more simulation accuracy per unit computation. However, the relative simulation error from coarser spatial resolution generally exceeds that from longer operator duration; e.g., degrading from $2^{\circ} \times 2.5^{\circ}$ to $4^{\circ} \times 5^{\circ}$ increases error by an order of magnitude. We recommend prioritizing fine spatial resolution before considering different operator durations in offline chemistry-transport models. We encourage chemistry-transport model users to specify in publications the durations of operators due to their effects on simulation accuracy.

\section{Introduction}

Global and regional chemistry-transport models (CTMs) have a wide range of applications in studies of climate, air quality, and biogeochemical cycling. The last few decades have witnessed rapid development of modeling sophistication to tackle these issues, but that development is associated with increasing computational expense. Typically, Eulerian models divide the atmosphere into numerous $\left(10^{4}-10^{8}\right)$ grid boxes and solve the mass continuity equation to simulate atmospheric composition. Numerical solution of the mass continuity equation involves separating the different chemical and transport processes (or operators) through operator split- 
ting. The concentrations of simulated species are sensitive to the duration of operators used in the CTM. Attention is needed to understand how operator duration affects model performance.

Numerous studies have examined the sensitivity of simulations to grid resolution for ozone (Jang et al., 1995; Esler et al., 2004; Ito et al., 2009; Yu et al., 2016), ozone production efficiency (Liang and Jacobson, 2000), and ozone sensitivity to precursor emissions (Cohan et al., 2006; Henderson et al., 2010). Simulation error increases proportional to the size of the horizontal grid (Wild and Prather, 2006; Prather et al., 2008). Biases can be reduced by simulating sub-grid-scale processes such as emission plumes from point sources (Sillman et al., 1990; Valin et al., 2011), aircraft exhaust (Kraabøl et al., 2002), ship exhaust (Vinken et al., 2011), mineral dust emissions (Ridley et al., 2013), and lightning (Cooper et al., 2014). The spatial and temporal resolution of the meteorological fields used in CTMs can also influence model processes (Bian et al., 2009). The spatiotemporal variation of carbon monoxide is better represented with finer grid resolution (Wang et al., 2004; Chen et al., 2009; Yan et al., 2014). Moreover, fine horizontal resolution is important for air quality exposure assessment and health impact studies (Punger and West, 2013; Fountoukis et al., 2013; Thompson et al., 2014; Li et al., 2015). Fine vertical resolution can better represent the effects of convection (Rind et al., 2007; Arteta et al., 2009). Simulations are also sensitive to operator durations (Mallet et al., 2007; Santillana et al., 2016), however, few studies have examined this sensitivity.

CTMs solve the continuity equation for tens to hundreds of chemical species, each with number density $n$, for individual grid boxes defined in the Eulerian model.

$$
\frac{\partial n}{\partial t}=-\nabla \times n \boldsymbol{U}+P-L
$$

$\partial n / \partial t$ represents the local temporal evolution of $n .-\nabla \times$ $n \boldsymbol{U}$ represents the transport flux divergence term, where $\boldsymbol{U}$ is the wind velocity vector. $P$ and $L$ are the local production and loss terms respectively. Typically, the above equation is discretized in space, and the continuity equation is simulated as a system of coupled nonlinear partial differential equations with chemical and transport operators. These chemical and transport operators are usually simulated sequentially through operator splitting to increase computational efficiency (Hundsdorfer and Verwer, 2003). The transport operator involves solving the 3-D advection equation using efficient numerical schemes (Prather, 1986; Lin and Rood, 1996). Boundary layer mixing, convection, emission and deposition are often simulated as individual operators. The chemical operator representing the temporal evolution of local sources and sinks involves numerically solving a system of coupled ordinary differential equations using efficient solvers (Jacobson and Turco, 1994; Damian et al., 2002). The integration time step in a differential equation solver is important for efficient and accurate solution (Jacobson and
Turco, 1994). Moreover, the model accuracy is affected by the duration of chemical and transport operators (Mallet and Sportisse, 2006; Mallet et al., 2007), and the order in which these operators are applied (Sportisse, 2000; Santillana et al., 2016). The operator splitting method requires the coupling between individual operators to be negligible over the operator duration. However, reducing operator durations increases computational expense. Attention is needed to this tradeoff.

We examine the sensitivity of a CTM to operator duration by conducting a series of simulations at different horizontal resolutions and operator durations. We then identify the optimal operator duration from the range of operator durations from 10 to 60 min usually used by global CTMs (e.g., Horowitz et al., 2003; Huijnen et al., 2010). Section 2 describes the sensitivity simulations, the method to quantify the simulation error, as well as the method to identify the simulation operator durations that best account for both computational expense and simulation accuracy. Comparison of the sensitivity simulations, description of resolution-dependent errors, and the identification of appropriate chemical and transport operator durations are examined in Sect. 3.

\section{Materials and methods}

\subsection{GEOS-Chem simulations}

We conduct a series of sensitivity simulations with the GEOS-Chem CTM (version 10-01; www.geos-chem.org) at different horizontal resolutions and operator durations to examine the individual sensitivities to chemical and transport operator durations. The GEOS-Chem model (Bey et al., 2001 ) is used by about 100 research groups worldwide to simulate the oxidant-aerosol system. GEOS-Chem has the capability to be driven with several generations of assimilated meteorological data from the Goddard Earth Observing System (GEOS) at the NASA Global Modeling Assimilation Office (GMAO). For computational expedience, GEOSChem global simulations are often conducted using horizontal resolutions of either $4^{\circ} \times 5^{\circ}$ or $2^{\circ} \times 2.5^{\circ}$ degraded from the native resolution of GEOS meteorology. GEOS-Chem also has the capability for nested regional simulations where the global model provides dynamic boundary condition to the finer regional grids (Wang et al., 2004; Chen et al., 2009; Zhang et al., 2011; van Donkelaar et al., 2012). We use the GEOS-5.2.0 meteorology available at a native horizontal resolution of $0.5^{\circ} \times 0.667^{\circ}$ (Rienecker et al., 2008). It includes $3 \mathrm{~h}$ averaged 2-D fields such as mixed layer depth, and $6 \mathrm{~h}$ averaged 3-D fields such as zonal and meridional wind, and convective mass flux. The height of the lowest level of the model is approximately $130 \mathrm{~m}$ above the sea level, with 47 vertical levels.

GEOS-Chem performs species advection $(A)$, vertical mixing $(V)$, cloud convection $(Z)$ and wet deposition $(W)$ for every transport operator duration $(T)$, as well as dry deposi- 
tion $(D)$, emissions $(E)$, and chemistry $(G)$ for every chemical operator duration $(C)$ in the following order,

$A(T) \times D(C) \times E(C) \times V(T) \times Z(T) \times G(C) \times W(T)$

The traditional transport operator durations are $30 \mathrm{~min}$ at $4^{\circ} \times 5^{\circ}$ resolution, $15 \mathrm{~min}$ at $2^{\circ} \times 2.5^{\circ}$ resolution, and $10 \mathrm{~min}$ at $0.5^{\circ} \times 0.667^{\circ}$ resolution. The traditional chemical operator duration is set to either 60 min or twice the transport operator duration based on the Strang operator splitting scheme (Strang, 1968) which follows $T \times C \times T \times T \times C \times T$ order repetitively with $C=2 \times T$. Transport operations are repeated twice before a chemical operation when $C=2 \times T$. We also consider an alternate splitting scheme, which follows $T \times C \times T \times C$ order, repetitively, with $C=T$. Changes in operator duration from $C=2 \times T$ to $C=T$ include effects of both time truncation $(T \times T$ to $T)$ and operator splitting.

Advection is based on the multi-dimensional flux-form semi-Lagrangian advection scheme (Lin and Rood, 1996; Lin et al., 1994), with an additional pressure-fixer algorithm implemented for the conservation of species mass (Rotman et al., 2004). The cloud convection operator couples transport by convection (Balkanski et al., 1993; Wu et al., 2007) with gas-aerosol wet deposition (Liu et al., 2001; Wang et al., 2011; Amos et al., 2012). GEOS-Chem uses an internal integration time step of $5 \mathrm{~min}$ for convective mixing within the cloud convection operator. The wet deposition operator includes scavenging by large-scale precipitation through first order operators, rainout and washout (Balkanski et al., 1993). We use a non-local boundary layer mixing scheme for vertical transport (Holtslag and Boville, 1993; Lin and McElroy, 2010). Emissions are processed through the HEMCO module (Keller et al., 2014). A resistance-in-series method is used for dry deposition of species (Wesely, 1989; Wang et al., 1998; Zhang et al., 2001; Fisher et al., 2011).

GEOS-Chem uses a sparse matrix vectorized GEAR II chemistry solver (Jacobson and Turco, 1994; Jacobson, 1995, 1998). The oxidant-aerosol chemistry simulation includes organic and black carbon (Park et al., 2003), mineral dust (Fairlie et al., 2007; Zender et al., 2003; Ginoux et al., 2001), sea salt (Alexander et al., 2005; Jaeglé et al., 2011), and the sulfate-nitrate-ammonium system (Park et al., 2004). The photolysis frequency is calculated (Mao et al., 2010; Eastham et al., 2014) at the middle of the chemical operator duration using the Fast-JX algorithm (Bian and Prather, 2002). Simulation of gas-aerosol interactions are performed within the chemistry operator by aerosol extinction effects on photolysis rates (Martin et al., 2003), and heterogeneous chemistry (Jacob, 2000) including aerosol uptake of $\mathrm{N}_{2} \mathrm{O}_{5}$ (Evans and Jacob, 2005) and $\mathrm{HO}_{2}$ (Mao et al., 2013). The ISORROPIA II thermodynamic module (Fontoukis and Nenes, 2007) performs aerosol-gas partitioning (Pye et al., 2009).

We conduct simulations for 2010 July at two horizontal resolutions of $4^{\circ} \times 5^{\circ}$ and $2^{\circ} \times 2.5^{\circ}$ globally, and $0.5^{\circ} \times 0.667^{\circ}$ over the North America $\left(140-40^{\circ} \mathrm{W}, 10\right.$ $\left.70^{\circ} \mathrm{N}\right)$ and East Asia $\left(70-150^{\circ} \mathrm{W}, 11^{\circ} \mathrm{S}-55^{\circ} \mathrm{N}\right)$ nested re- gions. We use the $4^{\circ} \times 5^{\circ}$ global simulation to archive dynamic boundary conditions every $3 \mathrm{~h}$ for the nested simulations. We use a 1-month spin-up with each GEOS-Chem simulation to reduce the influence of initial conditions.

\subsection{Computing platform}

We conduct all simulations on the same computing platform to compare their computational performance. We use the Glooscap cluster of the Atlantic Computational Excellence Network (ACENET) Consortium of Canadian Universities (http://www.ace-net.ca/wiki/Glooscap). The operating system is Linux 4.8. We use Intel Fortran compiler version 12. Each GEOS-Chem simulation is submitted as a 16-thread parallelized job on a single node.

We calculate the CPU time for the month of July for each operator separately using the Fortran-intrinsic routine, CPU_TIME. We found this value identical to the one calculated using the Linux command "qacct $-\mathrm{j}$ ". To reduce the effects of other jobs on the shared cluster, we repeat simulations five times, while excluding data output operations to minimize sensitivity to system input/output, and use the median to represent CPU time. We also report the standard error over the five simulations.

\subsection{Assessing the relative simulation error}

We treat the simulation with the shortest operator duration as the most accurate. This approach exploits the reduction in error associated with coupling across operators as operator duration diminishes. Assessing simulation error vs. operator duration through comparison with observations is impaired by imperfect model processes, by the sparseness of measurements, and by model-observation representativeness biases. We take as "truth" the concentrations simulated with a chemical operator duration $(C)$ of $10 \mathrm{~min}$ and a transport operator duration $(T)$ of $5 \mathrm{~min}$ (represented as C10T05). Finer resolutions are computationally prohibitive. We define the relative simulation error $E_{\text {sim }}^{s}$ for species $s$ as the root mean square error (RMSE) of the species concentrations simulated with the finest resolution ("truth") and the simulation under consideration (Sim), normalized by the concentrations in simulation "truth",

$E_{\text {sim }}^{s}=\frac{\sqrt{N} \sqrt{\sum_{i=1}^{i=N}\left(\operatorname{Truth}_{i}^{s}-\operatorname{Sim}_{i}^{s}\right)^{2}}}{\sum_{i=1}^{i=N} \operatorname{Truth}_{i}^{s}}$

where, $i$ represents a particular grid box, with a total number of $N$ grid boxes of interest. RMSE in the numerator is chosen instead of absolute difference to more heavily penalize extrema. Normalization with the mass of the "true" simulation is intended to cross-compare $E_{\text {sim }}^{s}$ of different species. $E_{\text {sim }}^{s}$ captures the variation of a species $s$ from the "true" simulation. 

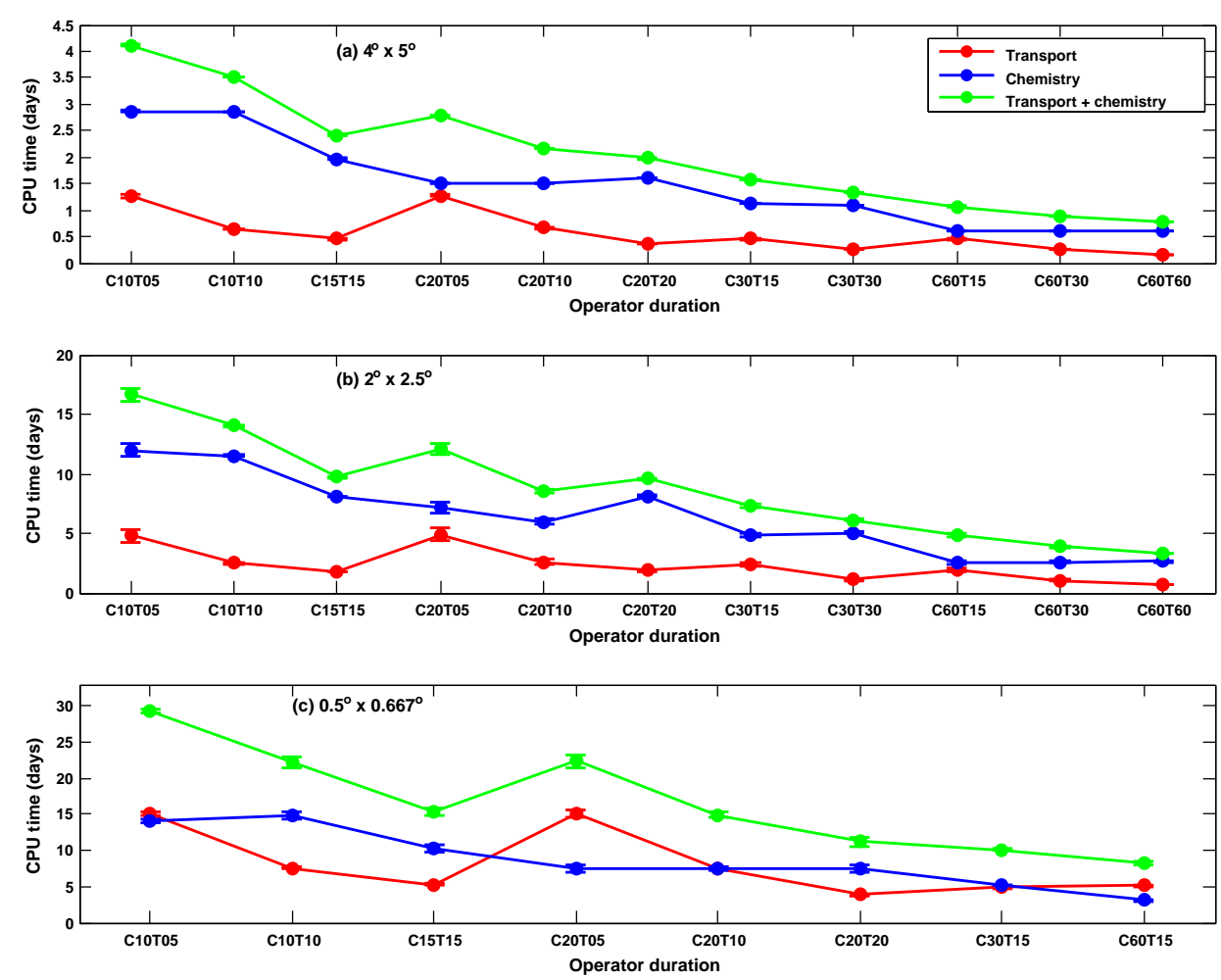

Figure 1. CPU time for GEOS-Chem simulations with various operator durations at three horizontal resolutions. Global simulations are at $4^{\circ} \times 5^{\circ}$ (a) and $2^{\circ} \times 2.5^{\circ}$ (b) resolutions. Panel (c) contains results for the average of two nested regions North America and East Asia at $0.5^{\circ} \times 0.667^{\circ}$ resolution. Colored lines represent the CPU time for simulating transport (red) and chemical (blue) operators, and the sum of the two (green). Error bars represent standard error over five simulations. Simulations are represented in the abscissa as CccTtt with chemical operator duration, $C=c c \mathrm{~min}$, and transport operator duration, $T=t t \min$.

We focus on four key species relevant to atmospheric chemistry, namely nitrogen oxides $\left(\mathrm{NO}_{x}=\mathrm{NO}+\mathrm{NO}_{2}\right)$, secondary inorganic aerosols (SIA: sum of sulfate, nitrate and ammonium), ozone $\left(\mathrm{O}_{3}\right)$, and carbon monoxide $(\mathrm{CO})$. These species represent a range of lifetimes from a day $\left(\mathrm{NO}_{x}\right)$ to weeks (CO). The focus on SIA is designed to devote more attention to chemically active species than to mineral dust and sea salt. We sample the instantaneous values of simulated ground-level concentrations of these atmospheric species every $60 \mathrm{~min}$ to span the diurnal variation of chemical environments. We focus on concentrations in July near the Earth's surface when and where chemical and transport timescales tend to be short.

\subsection{Identifying the optimal operator duration}

A practical way to select optimal chemical and transport operator durations is to identify the simulation with the lowest error $\left(E_{\text {sim }}^{s}\right)$ per unit of computation time. To quantify the simulation accuracy per unit CPU time, we propose a simple metric, the CPU-time adjusted composite normalized error (CNE) which represents a tradeoff between the simulation accuracy and the associated computation expense. This is performed by normalizing the relative simulation error $E_{\text {sim }}^{s}$ for species $s$ by the CPU time $t$ for the simulation under consideration $t_{\text {sim }}$ and for a reference simulation $t_{\text {ref }}$, and taking the mean of the four species.

$\mathrm{CNE}=\left(\frac{1}{4} \times \sum_{s} \frac{E_{\mathrm{sim}}^{s}}{E_{\mathrm{ref}}^{s}}\right) \times\left(\frac{t_{\mathrm{sim}}}{t_{\mathrm{ref}}}\right)$

We normalize $E_{\text {sim }}^{s}$ by the reference $E_{\text {ref }}^{s}$ so that the CPUtime adjusted composite normalized error for each species is of similar magnitude. The variation of $\mathrm{CNE}$ across operator durations is unaffected by the choice of reference simulation; C10T10 used here. The relative value of CPU time vs. simulation accuracy is subjective and depends on scientific objective. This definition of CNE gives equal weighting to the respective cost of CPU time and simulation accuracy. The simulation with the lowest CNE is used to identify an optimal chemical and transport operator duration.

\section{Results and discussion}

Figure 1 shows the computational performance for the series of GEOS-Chem simulations conducted here. The CPU time decreases by factors of 3-5 from fine to coarse operator duration. The CPU time increases by about a factor of 4 
(a)
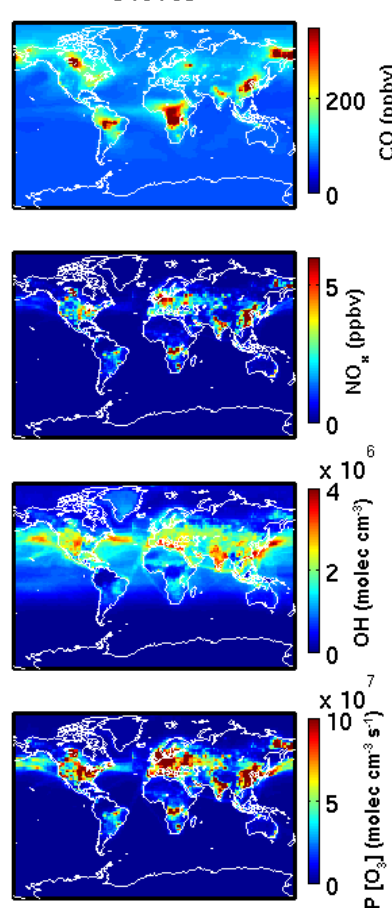

C10T10 - C10T05
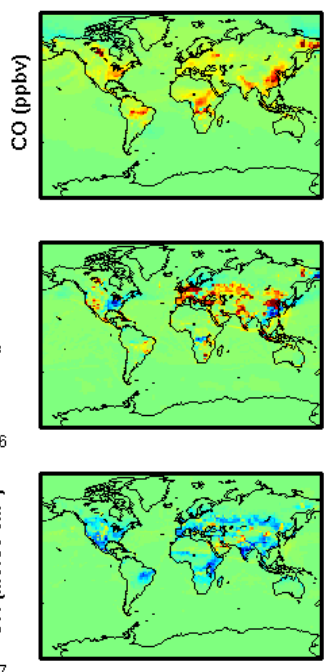

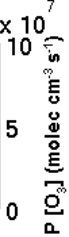

С20T05 - С10T05
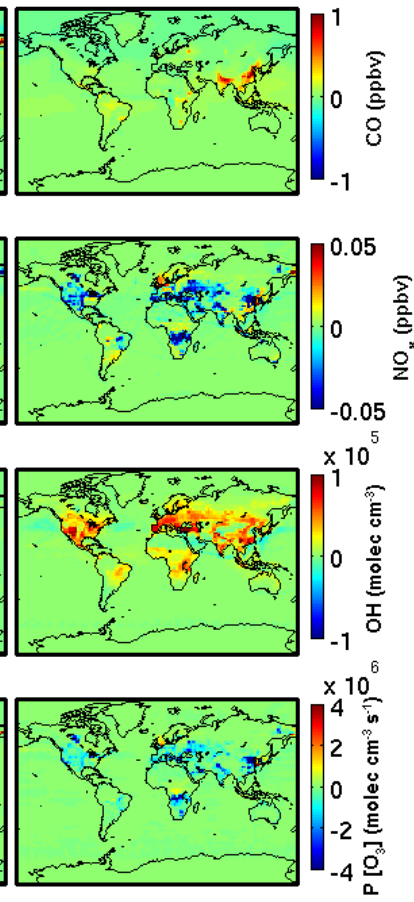

(b)
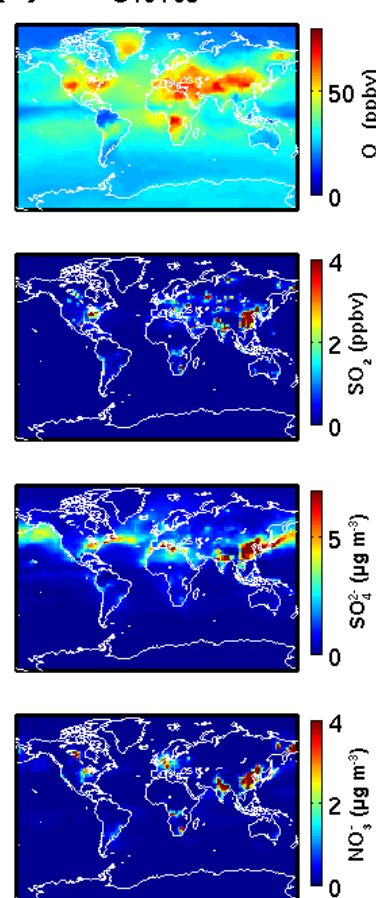
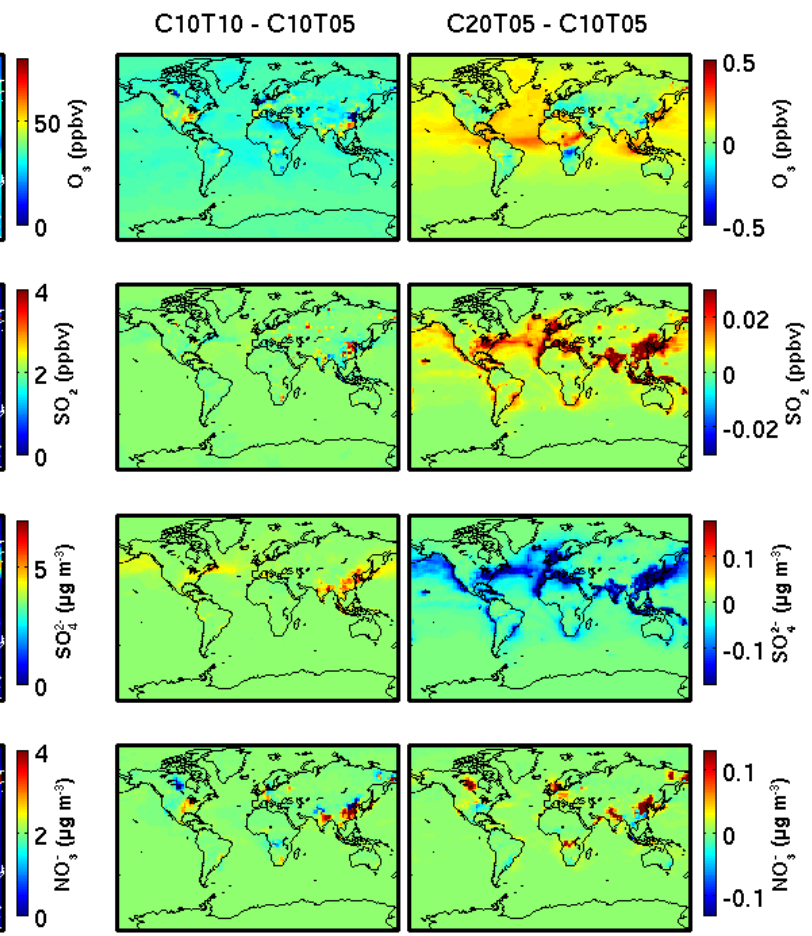

Figure 2. (a) Sensitivity of simulated species to the duration of chemical and transport operators. The left column contains monthly mean ground-level concentrations simulated with the shortest operator duration considered (C10T05) at $2^{\circ} \times 2.5^{\circ}$ horizontal resolution. Other columns contain the absolute differences from doubling the transport operator duration to C10T10 (middle), and doubling the chemical operator duration to $\mathrm{C} 20 \mathrm{~T} 05$ (right). Each row from top to bottom represents carbon monoxide (CO), nitrogen oxides $\left(\mathrm{NO}_{x}\right)$, hydroxyl radical $(\mathrm{OH})$, and the production of ozone $\left(P\left[\mathrm{O}_{3}\right]\right)$. Simulations are represented as $C c c T t t$ with chemical operator duration, $C=c c$ min, and transport operator duration, $T=t t \mathrm{~min}$. (b) As described in panel (a), but each row from top to bottom represents ozone $\left(\mathrm{O}_{3}\right)$, sulfur dioxide $\left(\mathrm{SO}_{2}\right)$, sulfate $\left(\mathrm{SO}_{4}^{2-}\right)$, and nitrate $\left(\mathrm{NO}_{3}^{-}\right)$. 
${ }^{N O}{ }_{X}$
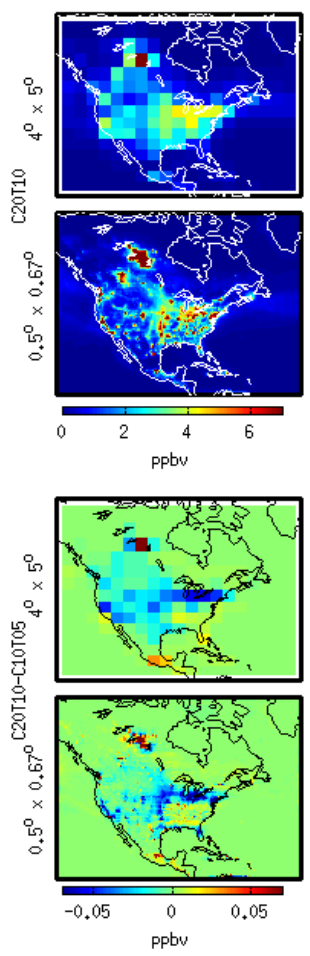

SIA
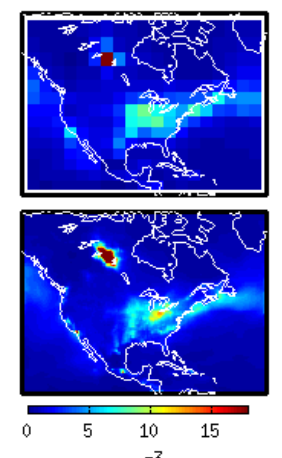

ug $m^{-3}$
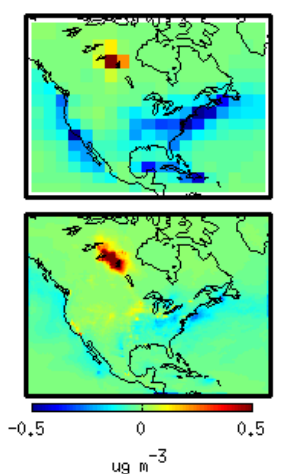

$0_{3}$
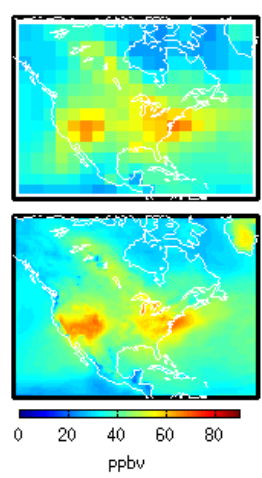

Ppbo
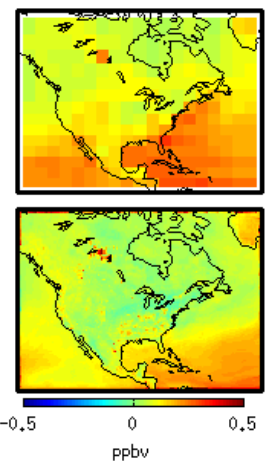

Co
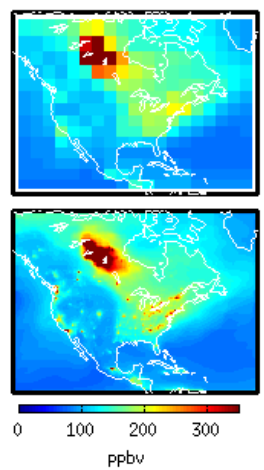

$\mathrm{ppb}$
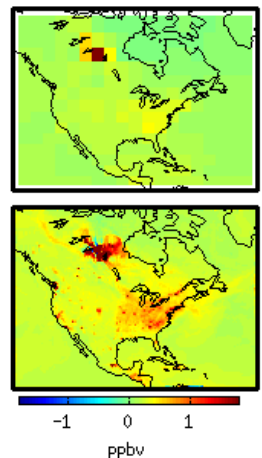

Figure 3. Sensitivity of simulated species to changes in operator duration (C20T10 to C10T05) at two different horizontal resolutions over North America (global $4^{\circ} \times 5^{\circ}$, and nested $0.5^{\circ} \times 0.67^{\circ}$ simulations). The upper two rows contain monthly mean ground-level concentrations simulated with the $\mathrm{C} 20 \mathrm{~T} 10$ operator duration for $4^{\circ} \times 5^{\circ}$ (top row) and $0.5^{\circ} \times 0.67^{\circ}$ (second row) resolutions. The two lower rows contain the monthly mean differences (C20T10 minus C10T05) for $4^{\circ} \times 5^{\circ}$ (third row) and $0.5^{\circ} \times 0.67^{\circ}$ (bottom row) resolutions. Each column from left to right represents nitrogen oxides $\left(\mathrm{NO}_{x}\right)$, secondary inorganic aerosols $(\mathrm{SIA})$, ozone $\left(\mathrm{O}_{3}\right)$, and carbon monoxide $(\mathrm{CO})$.

from $4^{\circ} \times 5^{\circ}$ to $2^{\circ} \times 2.5^{\circ}$ and another factor of 2 to a single nested simulation at $0.5^{\circ} \times 0.667^{\circ}$. The linearity from $4^{\circ} \times 5^{\circ}$ to $2^{\circ} \times 2.5^{\circ}$ implies that grid boxes are sufficiently large that CPU time is proportional to the number of grid boxes, and that transport integration time steps constrained by the Courant-Freidrich-Lewy criterion (Courant et al., 1967) are largely unaffected by changes to grid box size at these resolutions. Comparison of individual CPU times for chemical and transport operators shows that performing a single cycle of all chemical operations takes $\sim 4$ times that of a single cycle of transport operations at the global scale. This factor is reduced for nested simulations due in part to the additional CPU time for simulating boundary conditions.

Figure 2 illustrates the sensitivity of the simulations to chemical and transport operators at $2^{\circ} \times 2.5^{\circ}$ horizontal resolution. The left column shows the species concentrations for the "true" simulation (C10T05). The middle column shows the difference in species concentrations from doubling the transport operator duration. This doubling is in practice a change in time truncation of the transport operator from $T \times C \times T \times T \times C \times T$ to $T \times C \times T \times C$ since the transport operator must keep pace with the chemistry operator. Increasing the transport operator duration tends to increase concentra- tions of emitted species like $\mathrm{CO}$ and $\mathrm{NO}_{x}$ over source regions since species are more uniformly mixed by long continuous operator durations before loss processes such as dry deposition and chemistry occur. More homogeneous fields have lower dry deposition rates as a larger fraction is mixed aloft, and lower chemical loss rates depending on the chemical regime. The increase in $\mathrm{CO}$ over source regions is partly associated with decreases in $\mathrm{OH}$. Increasing concentrations of ozone precursors increases ozone production $\left(P\left[\mathrm{O}_{3}\right]\right)$. Wild and Prather (2006) similarly found that ozone production increases at coarser horizontal resolution. Increasing the transport operator duration increases SIA components, especially over the source regions of East Asia, northern India, and North America.

The right column in Fig. 2 shows the change in species concentrations from increasing the chemical operator duration. Hydroxyl radical concentrations increase, $\mathrm{NO}_{x}$ concentrations decrease, and $P\left[\mathrm{O}_{3}\right]$ decreases with increasing chemical operator durations over source regions. Berntsen and Isaken (1997) found that the error introduced by coarser chemical operator durations is higher in polluted regions than the clean background due to the increased time lag, and invariant production and loss across rapid chemical cycles. A 

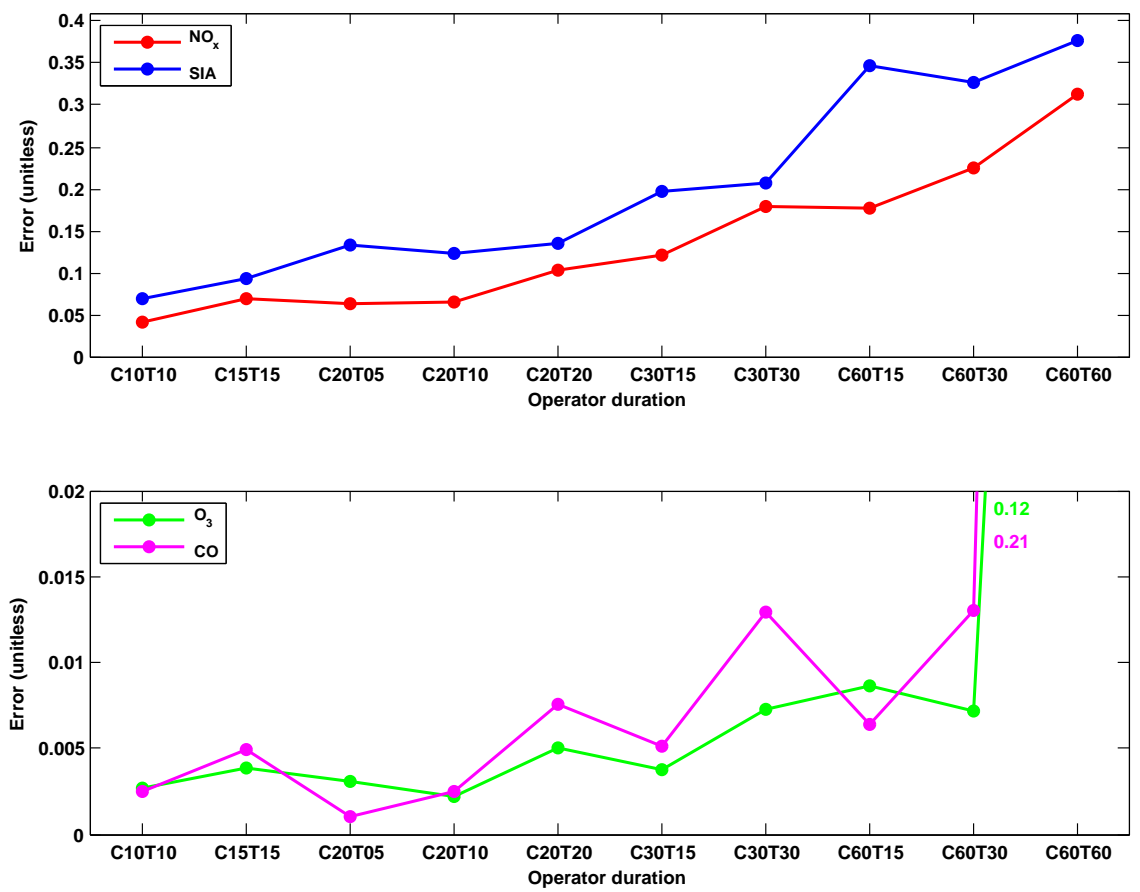

Figure 4. Relative simulation error of different species $\left(E_{\text {sim }}^{s}\right.$, Eq. 3) with various operator durations at $2^{\circ} \times 2.5^{\circ}$ horizontal resolution. Colored lines and dots represent the relative simulation error for nitrogen oxides $\left(\mathrm{NO}_{x}\right.$; red), secondary inorganic aerosols (SIA; blue), ozone $\left(\mathrm{O}_{3}\right.$; green), and carbon monoxide (CO; magenta). Simulations are represented in the abscissa as $C c c T t t$ with chemical operator duration, $C=c c \mathrm{~min}$, and transport operator duration, $T=t t \mathrm{~min}$.

longer chemical operator duration decreases sulfate and ammonium but increases nitrate over source regions. Inspection of $\mathrm{SO}_{2}$ and $\mathrm{H}_{2} \mathrm{O}_{2}$ fields indicates that sulfate formation through $\mathrm{H}_{2} \mathrm{O}_{2}$ in clouds decreases at longer chemical operator durations. In turn, $\mathrm{SO}_{2}$ and $\mathrm{NH}_{3}$ concentrations increase at longer chemical operator durations due to the corresponding decreases in ammonium sulfate or ammonium bisulfate. The additional free ammonia at longer chemical operator durations tends to promote regional ammonium nitrate formation depending on local thermodynamics. An increase of total SIA mass with increasing chemical operator duration is driven by nitrate and ammonium, and partially compensated by a reduction in sulfate, especially downwind of source regions. We find similar spatial patterns for other operator duration combinations, and other horizontal resolutions.

Figure 3 shows the sensitivity of simulated species to changes in operator duration (C20T10 to C10T05) at two other horizontal resolutions (global $4^{\circ} \times 5^{\circ}$, and nested North America $0.5^{\circ} \times 0.67^{\circ}$ simulations) considered here. Spatial patterns of monthly mean ground-level concentrations, and absolute differences are similar, albeit with finer spatial heterogeneity resolved in the nested simulation. However, some resolution dependent differences do arise reflecting nonlinear feedbacks.

Figures 4 shows the relative simulation error for nitrogen oxides, secondary inorganic aerosols, ozone and carbon monoxide with varying operator durations at $2^{\circ} \times 2.5^{\circ}$ hor- izontal resolution. Relative simulation errors for all these major species increase by more than a factor of 5 from the shortest to longest operator duration. Errors increase fairly smoothly with increasing chemical and transport operator duration until the transport operator duration exceeds $30 \mathrm{~min}$. Then errors increase by an order of magnitude for long lived species of $\mathrm{O}_{3}$ and $\mathrm{CO}$. The saw-tooth pattern for $\mathrm{CO}$ vs. $\mathrm{O}_{3}$ reflects a greater sensitivity of $\mathrm{CO}$ to transport operator duration and a greater sensitivity of $\mathrm{O}_{3}$ to chemical operator duration. Relative simulation errors for other horizontal resolutions follow similar pattern. These relative errors of 5$35 \%$ for $\mathrm{NO}_{x}$ and SIA are comparable to typical modelobservation errors of $\sim 30 \%$ for $\mathrm{NO}_{x}$ (Boersma et al., 2008; Hudman et al., 2007) and 20-40\% for SIA (Philip et al., 2014; Heald et al., 2012). Operator duration errors of $<2 \%$ for $\mathrm{O}_{3}$ and $\mathrm{CO}$ are smaller than typical model-observation errors of $\sim 20 \%$ for ozone (Zhang et al., 2011; Wang et al., 2009) and 10-20\% for CO (Duncan et al., 2007; Shindell et al., 2006).

Figure 5 shows the difference in simulated species at $2^{\circ} \times 2.5^{\circ}$ horizontal resolution for the GEOS-Chem traditional (C30T15) minus the finest operator durations considered (C10T05). The spatial variation for the monthly mean ground-level concentrations is generally within $5-15 \%$ for short lived species like $\mathrm{NO}_{x}$ and SIA, and within $1 \%$ for longer lived species like $\mathrm{O}_{3}$ and CO. Santillana et al. (2016) similarly found an upper limit of $10 \%$ for operator splitting 

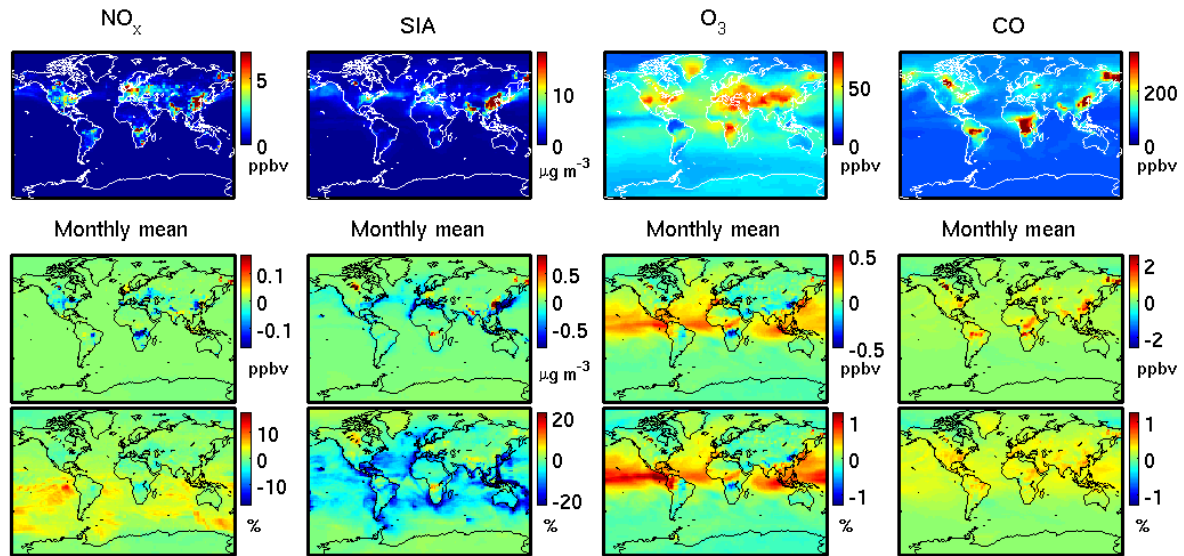

Monthly mean
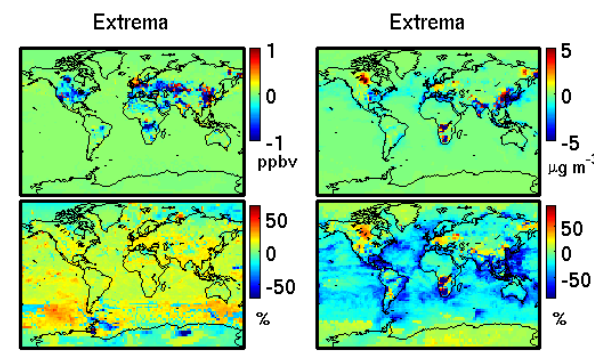

Extrema

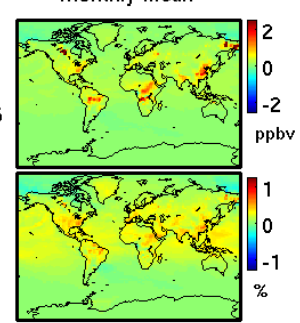

Extrema
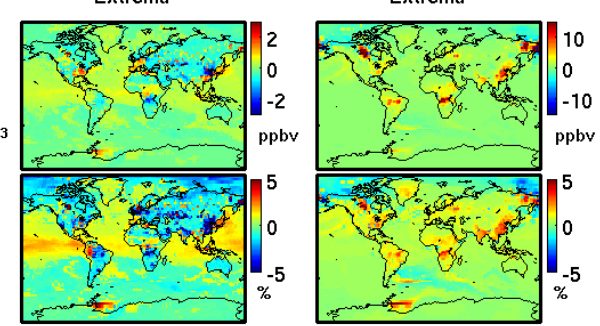

Figure 5. Effect on simulated species of changing from the GEOS-Chem traditional operator durations (C30T15) to the shortest operator durations considered (C10T05). The top row contains monthly mean ground-level concentrations simulated with the C30T15 operator duration at $2^{\circ} \times 2.5^{\circ}$ horizontal resolution. The next two rows contain the monthly mean differences (C30T15 minus C10T05) for absolute (second row) and relative (third row) differences. The two lowest rows contain the maximum differences (C30T15 minus C10T05) for absolute (fourth row) and relative (bottom row) differences. Each column from left to right represents nitrogen oxides $\left(\mathrm{NO}_{x}\right)$, secondary inorganic aerosols (SIA), ozone $\left(\mathrm{O}_{3}\right)$, and carbon monoxide $(\mathrm{CO})$.

errors. However, the maximum hourly spatial variation can exceed $50 \%$ for short lived species and $5 \%$ for longer lived species. The spatial pattern of extrema resembles that of the monthly mean, albeit with more heterogeneity from synoptic variation.

We also examined the diurnal variation and vertical profile of extrema. Extrema arise from all times of day with a slight tendency for larger values for $\mathrm{NO}_{x}$ at night, for $\mathrm{O}_{3}$ near sunrise and sunset, and for SIA and CO near noon. Zonal mean vertical profiles exhibit largest differences in the lower troposphere for $\mathrm{NO}_{x}$ and SIA, with more homogeneous differences throughout the troposphere for $\mathrm{O}_{3}$ and $\mathrm{CO}$. Near the subtropical jets of the upper troposphere $\mathrm{O}_{3}$ and $\mathrm{CO}$ have maximum extrema of up to $3 \%$.

Figure 6 shows the CPU-time adjusted composite normalized error for the GEOS-Chem simulations at various horizontal resolutions and operator durations. The CNE is significantly higher with $C=T$ than $C=2 \times T$. We confirmed this tendency with different choices of "truth" (such as C05T05, C10T10) or reference (such as C10T05) simulations. This finding motivates the traditional approach of using $C=2 \times T$ in GEOS-Chem simulations. Applying the chemical operator as frequently as the transport operator (with $C=T$ ) appears to increase computation cost with little benefit in ac- curacy. The CNEs for all three horizontal resolutions have noisy minima with a chemical operator duration of $20 \mathrm{~min}$ and a transport operator duration of $10 \mathrm{~min}$ (C20T10). A unit of computation time has a similar efficiency for a small range of operator durations from 10 to $20 \mathrm{~min}$. We found similar patterns in the variation of $\mathrm{CNE}$ with operator durations with CNE calculated for selected domains, such as over the Northern Hemisphere, nested model regions, land grid boxes, and over the entire troposphere. We conducted additional simulations at $4^{\circ} \times 5^{\circ}$ horizontal resolution for January 2011 with a spin-up of 7 months, and found similar patterns in CNE.

The relative simulation error decreases by $40-50 \%$ (Fig. 4) by changing the operator duration from the traditional (C30T15) to the optimal (C20T10) at $2^{\circ} \times 2.5^{\circ}$ horizontal resolution. The relative spatial variations are $<20 \%$ for $\mathrm{NO}_{x}$ and SIA, and $<1 \%$ for $\mathrm{O}_{3}$ and CO. However, the CPU time increases by $20 \%$ by the decrease in operator duration.

Table 1 shows the relative simulation error at $4^{\circ} \times 5^{\circ}$ horizontal resolution with "truth" at $2^{\circ} \times 2.5^{\circ}$ resolution (C10T05) to investigate the tradeoff between horizontal resolution and operator duration. The simulation error for all species at $4^{\circ} \times 5^{\circ}$ resolution increases by an order of magnitude compared to $2^{\circ} \times 2.5^{\circ}$ resolution for any choice of 


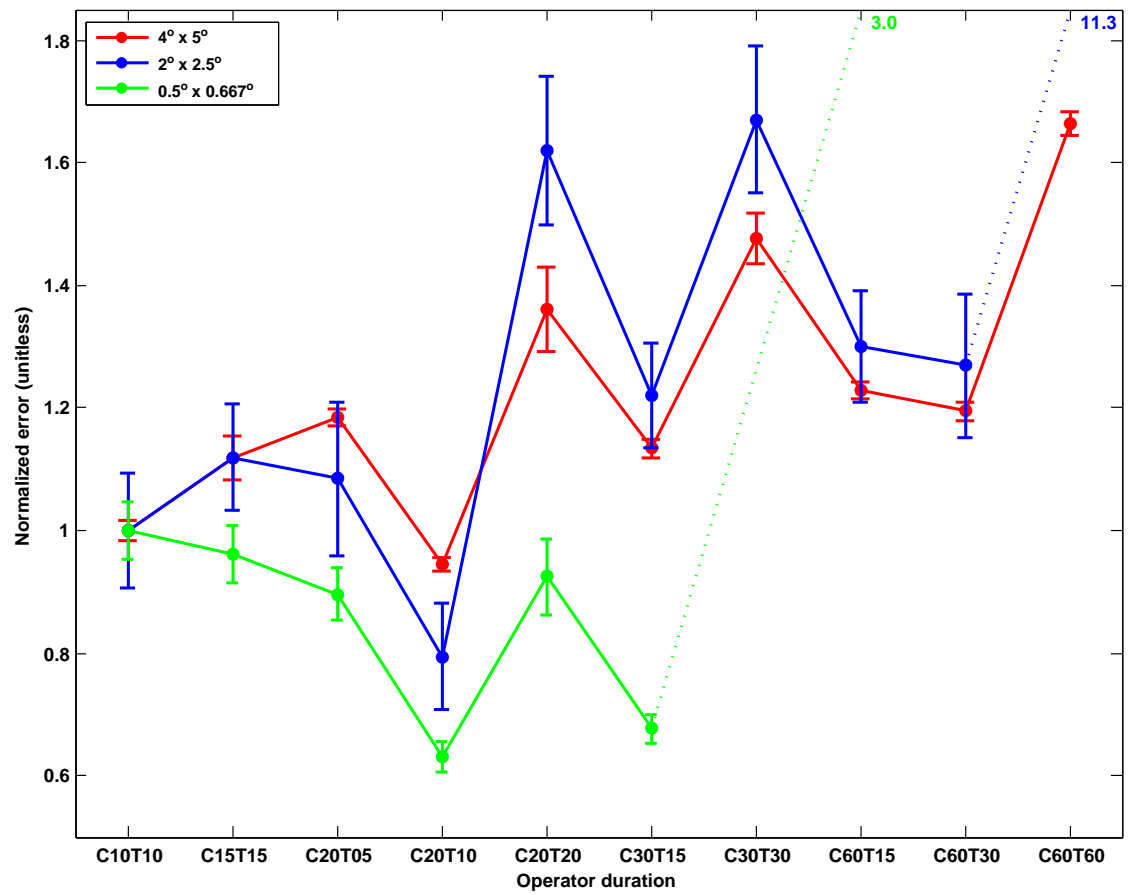

Figure 6. CPU-time adjusted composite normalized error (CNE, Eq. 4) for GEOS-Chem simulations with various horizontal resolutions and operator durations. Colored lines and dots represent the CNE for the global simulations at $4^{\circ} \times 5^{\circ}$ (red) and $2^{\circ} \times 2.5^{\circ}$ (blue), and the nested simulations at $0.5^{\circ} \times 0.667^{\circ}$ (green) horizontal resolutions. Error bars represent standard error in CPU time. Simulations are represented in the abscissa as $C c c T t t$ with chemical operator duration, $C=c c$ min, and transport operator duration, $T=t t \mathrm{~min}$.

Table 1. Comparison of mean* relative simulation error vs. horizontal resolution, with "truth" defined at $2^{\circ} \times 2.5^{\circ}$ horizontal resolution.

\begin{tabular}{lrr}
\hline Species & \multicolumn{2}{c}{ Mean relative simulation error (unitless) } \\
\cline { 2 - 3 } & $4^{\circ} \times 5^{\circ}$ resolution & $2^{\circ} \times 2.5^{\circ}$ resolution \\
\hline Nitrogen oxides & 2.1 & 0.092 \\
Secondary inorganic aerosols & 1.0 & 0.14 \\
Ozone & 0.17 & 0.004 \\
Carbon monoxide & 0.36 & 0.005 \\
\hline
\end{tabular}

* Mean taken for operator durations $\leq 30 \mathrm{~min}$.

operator duration tested here. The error in this configuration is insensitive to operator duration, and dominated by representativeness differences due to spatial structure resolved at $2^{\circ} \times 2.5^{\circ}$ resolution, but not at $4^{\circ} \times 5^{\circ}$ resolution. Nonlinear chemistry at different horizontal resolutions (e.g., Wild and Prather, 2006) also plays a role. Numerical errors due to advection processes generally exceed those from operator splitting (e.g., Prather et al., 2008; Santillana et al., 2016). We therefore recommend prioritizing horizontal resolution over operator duration for offline CTMs using time-averaged meteorological fields as tested here. As meteorological fields used in CTMs become available at finer temporal and spatial resolution, the value of shorter operator duration should further increase. We encourage CTM users to specify in publi- cation the duration of operators due to its effect on simulation accuracy.

\section{Conclusions}

The computational expense of chemistry-transport models warrants investigation into their efficiency and accuracy. Solving the continuity equation in CTMs through operator splitting method offers numerical efficiency, however, few studies have examined the implications of operator duration on simulation accuracy. We conducted simulations with the GEOS-Chem model for multiple choices of operator duration from 10 to $60 \mathrm{~min}$ as typically used by global CTMs. We found that longer continuous transport operator durations increase ozone precursors and ozone produc- 
tion over source regions since a more homogeneous distribution reduces loss through chemical reactions and dry deposition. Longer chemical operator durations decrease $\mathrm{NO}_{x}$ and ozone production over source regions. Longer chemical operator durations reduce sulfate and ammonium concentrations, however increase nitrate due to feedbacks with in-cloud $\mathrm{SO}_{2}$ oxidation and local aerosol thermodynamics.

We investigated the computational efficiency with the GEOS-Chem model, and found that the simulation computation time decreases by up to a factor of 5 from short (C10T05) to long (C60T60) operator duration. The chemical operator consumes about 4 times the CPU time of the transport operator. We subsequently compared the root mean square differences in the ground-level concentrations of nitrogen oxides, secondary inorganic aerosols (SIA), ozone and carbon monoxide with a finer temporal or spatial resolution taken as "truth", and estimated the relative simulation error. The relative simulation error for these species increases by more than a factor of 5 from the shortest to longest operator duration. Monthly mean simulation errors of about $30 \%$ for $\mathrm{NO}_{x}$ and SIA from long operator duration are comparable to typical model-observation errors, while simulation errors for $\mathrm{CO}$ and $\mathrm{O}_{3}$ tend to be less than $2 \%$ for operator duration $<30 \mathrm{~min}$.

In order to account for simulation accuracy with computational cost, we proposed a metric, CPU-time adjusted composite normalized error that identifies the operator duration with respect to CPU cost. We find greater efficiency of using $C=2 \times T$ than $C=T$ for all horizontal resolutions. The composite normalized error exhibits a noisy minimum for a chemical operator duration of $20 \mathrm{~min}$ and transport operator duration of $10 \mathrm{~min}$ for the range of operator durations and horizontal resolutions considered here. Nonetheless, the relative simulation error from changing horizontal resolution exceeds that from changing operator durations within a horizontal resolution. We recommend prioritizing fine spatial resolution before considering different operator durations in offline CTMs with time-averaged archived meteorological fields as tested here. The importance of shorter operator durations should increase with the availability of time-averaged meteorological fields at higher temporal resolution. Short operator durations could offer even greater benefits to simulation accuracy in online CTMs that offer meteorological fields at temporal resolutions closer to operator duration. We encourage CTM users to specify in publications the durations of operators due to their effects on simulation accuracy.

\section{Code availability}

The GEOS-Chem code is freely accessible to the public, by following the guidelines in http://wiki.geos-chem.org/. This work used GEOS-Chem version 10-01.

Acknowledgements. We thank Colette Heald, Daniel Jacob and Patrick Kim for useful comments at the early stages of this research. We are grateful to three anonymous reviewers for helpful comments. This work was supported by the National Science and Engineering Research Council, Canada, and the Atlantic Computational Excellence Network (http://www.ace-net.ca/).

Edited by: A. Kerkweg

\section{References}

Alexander, B., Park, R. J., Jacob, D. J., Li, Q. B., Yantosca, R. M., Savarino, J., Lee, C. C. W., and Thiemens, M. H.: Sulfate formation in sea-salt aerosols: Constraints from oxygen isotopes, J. Geophys. Res., 110, D10307, doi:10.1029/2004JD005659, 2005.

Amos, H. M., Jacob, D. J., Holmes, C. D., Fisher, J. A., Wang, Q., Yantosca, R. M., Corbitt, E. S., Galarneau, E., Rutter, A. P., Gustin, M. S., Steffen, A., Schauer, J. J., Graydon, J. A., Louis, V. L. St., Talbot, R. W., Edgerton, E. S., Zhang, Y., and Sunderland, E. M.: Gas-particle partitioning of atmospheric $\mathrm{Hg}$ (II) and its effect on global mercury deposition, Atmos. Chem. Phys., 12, 591-603, doi:10.5194/acp-12-591-2012, 2012.

Arteta, J., Marécal, V., and Rivière, E. D.: Regional modelling of tracer transport by tropical convection - Part 2: Sensitivity to model resolutions, Atmos. Chem. Phys., 9, 7101-7114, doi:10.5194/acp-9-7101-2009, 2009.

Balkanski, Y. J., Jacob, D. J., Gardner, G. M., Graustein, W. C., and Turekian, K. K.: Transport and residence times of tropospheric aerosols inferred from a global three-dimensional simulation of ${ }^{210} \mathrm{~Pb}$, J. Geophys. Res., 98, 20573-20586, doi:10.1029/93JD02456, 1993.

Berntsen, T. K. and Isaksen, I. S. A.: A global three-dimensional chemical transport model for the troposphere: 1. Model description and CO and ozone results, J. Geophys. Res., 102, 2123921280, doi:10.1029/97JD01140, 1997.

Bey, I., Jacob, D. J., Yantosca, R. M., Logan, J. A., Field, B. D., Fiore, A. M., Li, Q. B., Liu, H. G. Y., Mickley, L. J., and Schultz, M. G.: Global modeling of tropospheric chemistry with assimilated meteorology: Model description and evaluation, J. Geophys. Res., 106, 23073-23095, doi:10.1029/2001JD000807, 2001.

Bian, H. and Prather, M. J.: Fast-J2: Accurate simulation of stratospheric photolysis in global chemical models, J. Atmos. Chem., 41, 281-296, doi:10.1023/A:1014980619462, 2002.

Bian, H., Chin, M., Rodriguez, J. M., Yu, H., Penner, J. E., and Strahan, S.: Sensitivity of aerosol optical thickness and aerosol direct radiative effect to relative humidity, Atmos. Chem. Phys., 9, 2375-2386, doi:10.5194/acp-9-2375-2009, 2009.

Boersma, K. F., Jacob, D. J., Eskes, H. J., Pinder, R. W., Wang, J., and van der A, R. J.: Intercomparison of SCIAMACHY and OMI tropospheric $\mathrm{NO}_{2}$ columns: Observing the diurnal evolution of chemistry and emissions from space, J. Geophys. Res., 113, D16S26, doi:10.1029/2007JD008816, 2008.

Chen, D., Wang, Y., McElroy, M. B., He, K., Yantosca, R. M., and Le Sager, P.: Regional CO pollution and export in China simulated by the high-resolution nested-grid GEOS-Chem model, Atmos. Chem. Phys., 9, 3825-3839, doi:10.5194/acp-9-3825-2009, 2009. 
Cohan, D. S., Hu, Y., and Russell, A. G.: Dependence of ozone sensitivity analysis on grid resolution, Atmos. Environ., 40, 126135, doi:10.1016/j.atmosenv.2005.09.031, 2006.

Cooper, M., Martin, R. V., Wespes, C., Coheur, P., Clerbaux, C., and Murray, L. T.: Tropospheric nitric acid columns from the IASI satellite instrument interpreted with a chemical transport model: Implications for parameterizations of nitric oxide production by lightning, J. Geophys. Res.-Atmos., 119, 10068-10079, doi:10.1002/2014JD021907, 2014.

Courant, R., Friedrichs, K., and Lewy, H.: On partial difference equations of mathematical physics, IBM J. Res. Dev., 11, 215234, doi:10.1147/rd.112.0215, 1967.

Damian, V., Sandu, A., Damian, M., Potra, F., and Carmichael, G. R: The kinetic preprocessor KPP-a software environment for solving chemical kinetics, Comput. Chem. Eng., 26, 1567-1579, doi:10.1016/S0098-1354(02)00128-X, 2002.

Duncan, B. N., Logan, J. A., Bey, I., Megretskaia, I. A., Yantosca, R. M., Novelli, P. C., Jones, N. B., and Rinsland, C. P.: Global budget of CO, 1988-1997: Source estimates and validation with a global model, J. Geophys. Res., 112, D22301, doi:10.1029/2007JD008459, 2007.

Eastham, S. D., Weisenstein, D. K., and Barrett, S. R. H.: Development and evaluation of the unified troposphericstratospheric chemistry extension (UCX) for the global chemistry-transport model GEOS-Chem, Atmos. Environ., 89, 52-63, doi:10.1016/j.atmosenv.2014.02.001, 2014.

Esler, J. G., Roelofs, G. J., Köhler, M. O., and O'Connor, F. M.: A quantitative analysis of grid-related systematic errors in oxidising capacity and ozone production rates in chemistry transport models, Atmos. Chem. Phys., 4, 1781-1795, doi:10.5194/acp-41781-2004, 2004.

Evans, M. J. and Jacob, D. J.: Impact of new laboratory studies of $\mathrm{N}_{2} \mathrm{O}_{5}$ hydrolysis on global model budgets of tropospheric nitrogen oxides, ozone, and OH, Geophys. Res. Lett., 32, L09813, doi:10.1029/2005GL022469, 2005.

Fairlie, T. D., Jacob, D. J., and Park, R. J.: The impact of transpacific transport of mineral dust in the United States, Atmos. Environ., 41, 1251-1266, doi:10.1016/j.atmosenv.2006.09.048, 2007.

Fisher, J. A., Jacob, D. J., Wang, Q., Bahreini, R., Carouge, C. C., Cubison, M. J., Dibb, J. E., Diehl, T., Jimenez, J. L., Leibensperger, E. M., Lu, Z., Meinders, M. B. J., Pye, H. O. T., Quinn, P. K., Sharma, S., Streets, D. G., van Donkelaar, A., and Yantosca, R. M.: Sources, distribution, and acidity of sulfateammonium aerosol in the Arctic in winter-spring, Atmos. Environ., 45, 7301-7318, doi:10.1016/j.atmosenv.2011.08.030, 2011.

Fountoukis, C. and Nenes, A.: ISORROPIA II: a computationally efficient thermodynamic equilibrium model forK ${ }^{+}$$\mathrm{Ca}^{2+}-\mathrm{Mg}^{2+}-\mathrm{NH}_{4}^{+}-\mathrm{Na}^{+}-\mathrm{SO}_{4}^{2-}-\mathrm{NO}_{3}^{-}-\mathrm{Cl}^{-}-\mathrm{H}_{2} \mathrm{O}$ aerosols, Atmos. Chem. Phys., 7, 4639-4659, doi:10.5194/acp-7-4639-2007, 2007.

Fountoukis, C., Koraj, D., Denier van der Gon, H. A. C., Charalampidis, P. E., Pilinis, C., and Pandis, S. N.: Impact of grid resolution on the predicted fine $\mathrm{PM}$ by a regional 3D chemical transport model, Atmos. Environ., 68, 24-32, doi:10.1016/j.atmosenv.2012.11.008, 2013.

Ginoux, P., Chin, M., Tegen, I., Prospero, J. M., Holben, B., Duboviki, O., and Lin, S. J.: Sources and distributions of dust aerosols simulated with the GOCART model, J. Geophys. Res., 106, 20255-20274, doi:10.1029/2000JD000053, 2001.
Heald, C. L., Collett Jr., J. L., Lee, T., Benedict, K. B., Schwandner, F. M., Li, Y., Clarisse, L., Hurtmans, D. R., Van Damme, M., Clerbaux, C., Coheur, P.-F., Philip, S., Martin, R. V., and Pye, H. O. T.: Atmospheric ammonia and particulate inorganic nitrogen over the United States, Atmos. Chem. Phys., 12, 10295-10312, doi:10.5194/acp-12-10295-2012, 2012.

Henderson, B. H., Jeffries, H. E., Kim, B. U., and Vizuete, W. G.: The influence of model resolution on ozone in industrial volatile organic compound plumes, J. Air Waste Manage., 60, 11051117, doi:10.3155/1047-3289.60.9.1105, 2010.

Holtslag, A. A. M. and Boville, B. A.: Local Versus Nonlocal Boundary-Layer Diffusion in a Global Climate Model, J. Climate, 6, 1825-1842, doi:10.1175/15200442(1993)006<1825:LVNBLD>2.0.CO;2, 1993.

Horowitz, L. W., Walters, S., Mauzerall, D. L., Emmons, L. K., Rasch, P. J., Granier, C., Tie, X., Lamarque, J., Schultz, M. G., Tyndall, G. S., Orlando, J. J., and Brasseur, G. P.: A global simulation of tropospheric ozone and related tracers: Description and evaluation of MOZART, version 2, J. Geophys. Res., 108, 4784, doi:10.1029/2002JD002853, 2003.

Hudman, R. C., Jacob, D. J., Turquety, S., Leibensperger, E. M., Murray, L. T., Wu, S., Gilliland, A. B., Avery, M., Bertram, T. H., Brune, W., Cohen, R. C., Dibb, J. E., Flocke, F. M., Fried, A., Holloway, J., Neuman, J. A., Orville, R., Perring, A., Ren, X., Sachse, G. W., Singh, H. B., Swanson, A., and Wooldridge, P. J.: Surface and lightning sources of nitrogen oxides over the United States: Magnitudes, chemical evolution, and outflow, J. Geophys. Res., 112, D12S05, doi:10.1029/2006JD007912, 2007.

Huijnen, V., Williams, J., van Weele, M., van Noije, T., Krol, M., Dentener, F., Segers, A., Houweling, S., Peters, W., de Laat, J., Boersma, F., Bergamaschi, P., van Velthoven, P., Le Sager, P., Eskes, H., Alkemade, F., Scheele, R., Nédélec, P., and Pätz, H.-W.: The global chemistry transport model TM5: description and evaluation of the tropospheric chemistry version 3.0, Geosci. Model Dev., 3, 445-473, doi:10.5194/gmd-3-445-2010, 2010.

Hundsdorfer, W. and Verwer, J.: Numerical solution of timedependent advection-diffusion-reaction equations, Springer Series in Computational Mathematics, 33, 325-417, doi:10.1007/978-3-662-09017-6_4, 2003.

Ito, A., Sillman, S., and Penner J. E.: Global chemical transport model study of ozone response to changes in chemical kinetics and biogenic volatile organic compounds emissions due to increasing temperatures: Sensitivities to isoprene nitrate chemistry and grid resolution, J. Geophys. Res., 114, D09301, doi:10.1029/2008JD011254, 2009.

Jacob, D.: Heterogeneous chemistry and tropospheric ozone, Atmos. Environ., 34, 2131-2159, doi:10.1016/S13522310(99)00462-8, 2000.

Jacobson, M. and Turco, R. P.: SMVGEAR - a sparse-matrix, vectorized gear code for atmospheric models, Atmos. Environ., 28, 273-284, doi:10.1016/1352-2310(94)90102-3, 1994.

Jacobson, M. Z.: Computation of global photochemistry with SMVGEAR II, Atmos. Environ., 29, 2541-2546, doi:10.1016/1352-2310(95)00194-4, 1995.

Jacobson, M. Z.: Improvement of SMVGEAR II on vector and scalar machines through absolute error tolerance control, Atmos. Environ., 32, 791-796, doi:10.1016/S1352-2310(97)00315-4, 1998. 
Jaeglé, L., Quinn, P. K., Bates, T. S., Alexander, B., and Lin, J.-T.: Global distribution of sea salt aerosols: new constraints from in situ and remote sensing observations, Atmos. Chem. Phys., 11, 3137-3157, doi:10.5194/acp-11-3137-2011, 2011.

Jang, J. C., Jeffries, H. E., and Tonnesen, S.: Sensitivity of ozone to model grid resolution - II. Detailed process analysis for ozone chemistry, Atmos. Environ., 29, 3101-3114, doi:10.1016/13522310(95)00119-J, 1995.

Keller, C. A., Long, M. S., Yantosca, R. M., Da Silva, A. M., Pawson, S., and Jacob, D. J.: HEMCO v1.0: a versatile, ESMFcompliant component for calculating emissions in atmospheric models, Geosci. Model Dev., 7, 1409-1417, doi:10.5194/gmd-71409-2014, 2014.

Kraabøl, A. G., Berntsen, T. K., Sundet, J. K., and Stordal, F.: Impacts of $\mathrm{NO}_{x}$ emissions from subsonic aircraft in a global three-dimensional chemistry transport model including plume processes, J. Geophys. Res., 107, 4655, doi:10.1029/2001JD001019, 2002.

Li, Y., Henze, D. K., Jack, D., and Kinney, P.: The influence of air quality model resolution on health impact assessment for fine particulate matter and its components, Air Qual. Atmos. Health, 9, 51-68, doi:10.1007/s11869-015-0321-z, 2015.

Liang, J. and Jacobson, M. Z.: Effects of subgrid segregation on ozone production efficiency in a chemical model, Atmos. Environ., 34, 2975-2982, doi:10.1016/S1352-2310(99)00520-8, 2000.

Lin, J. and McElroy, M. B.: Impacts of boundary layer mixing on pollutant vertical profiles in the lower troposphere: Implications to satellite remote sensing, Atmos. Environ., 44, 1726-1739, doi:10.1016/j.atmosenv.2010.02.009, 2010.

Lin, S. and Rood, R. B.: Multidimensional FluxForm Semi-Lagrangian Transport Schemes, Mon. Weather Rev., 124, 2046-2070, doi:10.1175/15200493(1996)124<2046:MFFSLT>2.0.CO;2, 1996.

Lin, S., Chao, W. C., Sud, Y. C., and Walker, G. K.: A Class of the van Leer-type Transport Schemes and Its Application to the Moisture Transport in a General Circulation Model, Mon. Weather Rev., 122, 1575-1593, doi:10.1175/15200493(1994)122<1575:ACOTVL>2.0.CO;2, 1994.

Liu, H. Y., Jacob, D. J., Bey, I., and Yantosca, R. M.: Constraints from ${ }^{210} \mathrm{~Pb}$ and ${ }^{7} \mathrm{Be}$ on wet deposition and transport in a global three-dimensional chemical tracer model driven by assimilated meteorological fields, J. Geophys. Res., 106, 1210912128, doi:10.1029/2000JD900839, 2001.

Mallet, V. and Sportisse, B.: Uncertainty in a chemistry-transport model due to physical parameterizations and numerical approximations: An ensemble approach applied to ozone modeling, J. Geophys. Res., 111, D01302, doi:10.1029/2005JD006149, 2006.

Mallet, V., Pourchet, A., Quélo, D., and Sportisse, B.: Investigation of some numerical issues in a chemistry-transport model: Gas-phase simulations, J. Geophys. Res., 112, D15301, doi:10.1029/2006JD008373, 2007.

Mao, J., Jacob, D. J., Evans, M. J., Olson, J. R., Ren, X., Brune, W. H., Clair, J. M. St., Crounse, J. D., Spencer, K. M., Beaver, M. R., Wennberg, P. O., Cubison, M. J., Jimenez, J. L., Fried, A., Weibring, P., Walega, J. G., Hall, S. R., Weinheimer, A. J., Cohen, R. C., Chen, G., Crawford, J. H., McNaughton, C., Clarke, A. D., Jaeglé, L., Fisher, J. A., Yantosca, R. M., Le Sager, P., and Carouge, $\mathrm{C}$. : Chemistry of hydrogen oxide radicals $\left(\mathrm{HO}_{x}\right)$ in the Arctic troposphere in spring, Atmos. Chem. Phys., 10, 58235838, doi:10.5194/acp-10-5823-2010, 2010.

Mao, J., Fan, S., Jacob, D. J., and Travis, K. R.: Radical loss in the atmosphere from $\mathrm{Cu}-\mathrm{Fe}$ redox coupling in aerosols, Atmos. Chem. Phys., 13, 509-519, doi:10.5194/acp-13-509-2013, 2013.

Martin, R. V., Jacob, D. J., Yantosca, R. M., Chin, M., and Ginoux, P.: Global and regional decreases in tropospheric oxidants from photochemical effects of aerosols, J. Geophys. Res., 108, 4097, doi:10.1029/2002JD002622, 2003.

Park, R. J., Jacob, D. J., Chin, M., and Martin, R. V.: Sources of carbonaceous aerosols over the United States and implications for natural visibility, J. Geophys. Res.-Atmos., 108, 4355, doi:10.1029/2002JD003190, 2003.

Park, R. J., Jacob, D. J., Field, B. D., Yantosca, R. M., and Chin, M.: Natural and transboundary pollution influences on sulfate-nitrate-ammonium aerosols in the United States: Implications for policy, J. Geophys. Res.-Atmos., 109, D15204, doi:10.1029/2003JD004473, 2004.

Philip, S., Martin, R.V., van Donkelaar, A., Lo, J. W.-H., Wang, Y., Chen, D., Zhang, L., Kasibhatla, P. S., Wang, S. W., Zhang, Q., Lu, Z., Streets, D. G., Bittman, S., and Macdonald, D. J.: Global chemical composition of ambient fine particulate matter for exposure assessment, Environ. Sci. Technol., 48, 1306013068, doi:10.1021/es502965b, 2014.

Prather, M. J.: Numerical advection by conservation of second-order moments, J. Geophys. Res., 91, 6671-6681, doi:10.1029/JD091iD06p06671, 1986.

Prather, M. J., Zhu, X., Strahan, S. E., Steenrod, S. D., and Rodriguez, J. M.: Quantifying errors in trace species transport modeling, P. Natl. Acad. Sci. USA, 105, 19617-19621, doi:10.1073/pnas.0806541106, 2008.

Punger, E. M. and West, J. J.: The effect of grid resolution on estimates of the burden of ozone and fine particulate matter on premature mortality in the USA, Air Qual. Atmos. Health, 6, 563573, doi:10.1007/s11869-013-0197-8, 2013.

Pye, H. O. T., Liao, H., Wu, S., Mickley, L. J., Jacob, D. J., Henze, D. K., and Seinfeld, J. H.: Effect of changes in climate and emissions on future sulfate-nitrate-ammonium aerosol levels in the United States, J. Geophys. Res., 114, D01205, doi:10.1029/2008JD010701, 2009.

Ridley, D. A., Heald, C. L., Pierce, J. R., and Evans, M. J.: Toward resolution-independent dust emissions in global models: Impacts on the seasonal and spatial distribution of dust, Geophys. Res. Lett., 40, 2873-2877, doi:10.1002/grl.50409, 2013.

Rienecker, M. M., Suarez, M. J., Todling, R., Bacmeister, J., Takacs, L., Liu, H.-C., Gu, W., Sienkiewicz, M., Koster, R. D., Gelaro, R., Stajner, I., and Nielsen, J. E.: The GEOS-5 Data Assimilation System-Documentation of versions 5.0.1 and 5.1.0, and 5.2.0. NASA Tech. Rep. Series on Global Modeling and Data Assimilation, NASA/TM-2008-104606, vol. 27, Goddard Space Flight Center, Greenbelt, Maryland, USA, 92 p., 2008.

Rind, D., Lerner, J., Jonas, J., and McLinden, C.: Effects of resolution and model physics on tracer transports in the NASA Goddard Institute for Space Studies general circulation models, J. Geophys. Res., 112, D09315, doi:10.1029/2006JD007476, 2007.

Rotman, D. A., Atherton, C. S., Bergmann, D. J., Cameron-Smith, P. J., Chuang, C. C., Connel, P. S., Dignon, J. E., Franz, A., Grant, K. E., Kinnison, D. E., Molenkamp, C. R., Proctor, D. D., and Tannahill, J. R.: IMPACT, the LLNL 3-D global 
atmospheric chemical transport model for the combined troposphere and stratosphere: Model description and analysis of ozone and other trace gases, J. Geophys. Res., 109, D04303, doi:10.1029/2002JD003155, 2004.

Santillana, M., Zhang, L., and Yantosca, R.: Estimating numerical errors due to operator splitting in global atmospheric chemistry models: Transport and chemistry, J. Comput. Phys., 305, 372386, doi:10.1016/j.jcp.2015.10.052, 2016.

Shindell, D. T., Faluvegi, G., Stevenson, D. S., Krol, M. C., Emmons, L. K., Lamarque, J.-F., Petron, G., Dentener, F. J., Ellingsen, K., Schultz, M. G., Wild, O., Amann, M., Atherton, C. S., Bergmann, D. J., Bey, I., Butler, T., Cofala, J., Collins, W. J., Derwent, R. G., Doherty, R. M., Drevet, J., Eskes, H. J., Fiore, A. M., Gauss, M., Hauglustaine, D. A., Horowitz, L. W., Isaksen, I. S. A., Lawrence, M. G., Montanaro, V., Muller, J. F., Pitari, G., Prather, M. J., Pyle, J. A., Rast, S., Rodriguez, J. M., Sanderson, M. G., Savage, N. H., Strahan, S. E., Sudo, K., Szopa, S., Unger, N., van Noije, T. P. C., and Zeng, G.: Multimodel simulations of carbon monoxide: Comparison with observations and projected near-future changes, J. Geophys. Res., 111, D19306, doi:10.1029/2006JD007100, 2006.

Sillman, S., Logan, J. A., and Wofsy, S. C.: A regional scale model for ozone in the United States with subgrid representation of urban and power plant plumes, J. Geophys. Res., 95, 5731-5748, doi:10.1029/JD095iD05p05731, 1990.

Sportisse, B.: An analysis of operator splitting techniques in the stiff case, J. Comput. Phys., 161, 140-168, doi:10.1006/jcph.2000.6495, 2000.

Strang, G.: On the construction and comparison of difference schemes, SIAM J. Numer. Anal., 5, 506-517, doi:10.1137/0705041, 1968.

Thompson, T. M., Saari, R. K., and Selin, N. E.: Air quality resolution for health impact assessment: influence of regional characteristics, Atmos. Chem. Phys., 14, 969-978, doi:10.5194/acp14-969-2014, 2014.

Valin, L. C., Russell, A. R., Hudman, R. C., and Cohen, R. C.: Effects of model resolution on the interpretation of satellite $\mathrm{NO}_{2}$ observations, Atmos. Chem. Phys., 11, 11647-11655, doi:10.5194/acp-11-11647-2011, 2011.

van Donkelaar, A., Zhang, L., Chen, D., Martin, R. V., Pasch, A. N., Szykman, J. J., and Wang, Y. X.: Improving the accuracy of daily satellite-derived ground-level fine aerosol concentration estimates for North America, Environ. Sci. Technol., 46, 1197111978, doi:10.1021/es3025319, 2012.

Vinken, G. C. M., Boersma, K. F., Jacob, D. J., and Meijer, E. W.: Accounting for non-linear chemistry of ship plumes in the GEOS-Chem global chemistry transport model, Atmos. Chem. Phys., 11, 11707-11722, doi:10.5194/acp-11-11707-2011, 2011.

Wang, H., Jacob, D. J., Le Sager, P., Streets, D. G., Park, R. J., Gilliland, A. B., and van Donkelaar, A.: Surface ozone background in the United States: Canadian and Mexican pollution influences, Atmos. Environ., 43, 1310-1319, doi:10.1016/j.atmosenv.2008.11.036, 2009.
Wang, Q., Jacob, D. J., Fisher, J. A., Mao, J., Leibensperger, E. M., Carouge, C. C., Le Sager, P., Kondo, Y., Jimenez, J. L., Cubison, M. J., and Doherty, S. J.: Sources of carbonaceous aerosols and deposited black carbon in the Arctic in winter-spring: implications for radiative forcing, Atmos. Chem. Phys., 11, 1245312473, doi:10.5194/acp-11-12453-2011, 2011.

Wang, Y., Jacob, D. J., and Logan, J. A.: Global simulation of tropospheric $\mathrm{O}_{3}-\mathrm{NO}_{x}$-hydrocarbon chemistry: 1 . Model formulation, J. Geophys. Res., 103, 10713-10725, doi:10.1029/98JD00158, 1998.

Wang, Y. X., McElroy, M. B., Jacob D. J., and Yantosca, R. M.: A nested grid formulation for chemical transport over Asia: Applications to CO, J. Geophys. Res., 109, D22307, doi:10.1029/2004JD005237, 2004.

Wesely, M. L.: Parameterization of surface resistances to gaseous dry deposition in regional-scale numerical models, Atmos. Environ., 23, 1293-1304, doi:10.1016/0004-6981(89)90153-4, 1989.

Wild, O. and Prather, M. J.: Global tropospheric ozone modeling: Quantifying errors due to grid resolution, J. Geophys. Res., 111, D11305, doi:10.1029/2005JD006605, 2006.

Wu, S., Mickley, L. J., Jacob, D. J., Logan, J. A., Yantosca, R. M., and Rind, D.: Why are there large differences between models in global budgets of tropospheric ozone?, J. Geophys. Res., 112, D05302, doi:10.1029/2006JD007801, 2007.

Yan, Y.-Y., Lin, J.-T., Kuang, Y., Yang, D., and Zhang, L.: Tropospheric carbon monoxide over the Pacific during HIPPO: two-way coupled simulation of GEOS-Chem and its multiple nested models, Atmos. Chem. Phys., 14, 12649-12663, doi:10.5194/acp-14-12649-2014, 2014.

Yu, K., Jacob, D. J., Fisher, J. A., Kim, P. S., Marais, E. A., Miller, C. C., Travis, K. R., Zhu, L., Yantosca, R. M., Sulprizio, M. P., Cohen, R. C., Dibb, J. E., Fried, A., Mikoviny, T., Ryerson, T. B., Wennberg, P. O., and Wisthaler, A.: Sensitivity to grid resolution in the ability of a chemical transport model to simulate observed oxidant chemistry under high-isoprene conditions, Atmos. Chem. Phys., 16, 4369-4378, doi:10.5194/acp-16-43692016, 2016.

Zender, C. S., Bian, H., and Newman, D.: The mineral dust entrainment and deposition (DEAD) model: description and 1990s dust climatology, J. Geophys. Res., 108, 4416, doi:10.1029/2002JD002775, 2003.

Zhang, L., Jacob, D. J., Downey, N. V., Wood, D. A., Blewitt, D., Carouge, C. C., van Donkelaar, A., Jones, D. B. A., Murray, L. T., and Wang, Y.: Improved estimate of the policy-relevant background ozone in the United States using the GEOS-Chem global model with $1 / 2^{\circ} \times 2 / 3^{\circ}$ horizontal resolution over North America, Atmos. Environ., 45, 6769-6776, doi:10.1016/j.atmosenv.2011.07.054, 2011.

Zhang, L. M., Gong, S. L., Padro, J. and Barrie, L.: A size-segregated particle dry deposition scheme for an atmospheric aerosol module, Atmos. Environ., 35, 549-560, doi:10.1016/S1352-2310(00)00326-5, 2001. 